\title{
ANALISIS NILAI TAMBAH DAN STRATEGI PENGEMBANGAN USAHA PENGOLAHAN PISANG PADA UMKM KERIPIK TIGA BUJANG DI KOTA PONTIANAK
}

\author{
Samina Naton ${ }^{1}$, Dody Radiansah ${ }^{2}$, Hardiwan Juniansyah ${ }^{3}$ \\ Program Studi Manajemen Perkebunan, Jurusan Teknologi Pertanian Politeknik Negeri \\ Pontianak Indonesia \\ *Kontakpenulis: saminanaton1@gmail.com
}

\begin{abstract}
This study aims to determine the cost, revenue, profit, and $R$ / $C$ ratio, internal and external factors that influence the development of banana chips agroindustry, an alternative strategy that can be applied in the development of banana chips agroindustry in Pontianak City. The type of research used in this study is the case study method. Data collected includes primary data and secondary data. The respondent's withdrawal in this study was purposive sampling, which was determining the sample with consideration of certain criteria which looked at being able to provide maximum data, then the respondents who were taken were banana chips entrepreneurs and as supporting respondents namely one person. Agriculture Service and one person from academia. The results showed that the total costs incurred by banana chips entrepreneurs in one month of the production process amounted to $R p$. $22,030,029$, revenues amounting to $R p$. 46,090,000, the profits amounting to $R p$. 24,059,971 and added value of $R p .15,114$ / $\mathrm{kg}$ of raw materials. $R$ / C ratio of 2.09, which means that every expenditure of $R p .1 .00$ banana chips businessmen get a profit of $R p .2 .09$ which means that the business of banana chips is worth trying. The development strategy that can be done by banana chips entrepreneurs is an aggressive strategy with more focus on the strategy of SO (StrengthOpportunities), namely by using the power to take advantage of the opportunities that exist. SO (Strength-Opportunities) strategies include: (a) Increasing economic production capacity to meet demand, (b) Use of Technology, (c) Enlarging market share, (d) Maintaining the quality of banana chips products, and (e) Making product innovations.
\end{abstract}

Key words : cost, revenue, $R / C$ ratio, value added, business devoloping strategi and banana chips.

\section{Abstrak}

Penelitian ini bertujuan untuk mengetahui biaya, pendapatan, laba, dan $\mathrm{R} / \mathrm{C}$ rasio, faktor internal dan eksternal yang mempengaruhi pengembangan agroindustri keripik pisang, strategi alternatif yang dapat diterapkan dalam pengembangan agroindustri keripik pisang di Kota Pontianak. Jenis penelitian yang digunakan dalam penelitian ini adalah metode studi kasus. Data yang dikumpulkan meliputi data primer dan data sekunder. Penarikan responden dalam penelitian ini adalah purposive sampling, yaitu penentuan sampel dengan pertimbangan kriteria tertentu yang dipandang mampu memberikan data maksimal, maka responden yang diambil adalah pengusaha keripik pisang dan sebagai responden pendukung yaitu satu orang. Penyuluh Pertanian dan satu orang dari akademisi. Hasil penelitian menunjukkan bahwa total biaya yang dikeluarkan oleh pengusaha keripik pisang dalam satu bulan proses produksi adalah sebesar Rp. 22.030.029, pendapatan sebesar Rp. 46.090.000, keuntungan sebesar Rp. 24.059.971 dan nilai tambah Rp. 15.114 / kg bahan baku. 
$\mathrm{R} / \mathrm{C}$ ratio 2,09, artinya setiap pengeluaran sebesar Rp. 1,00 pengusaha keripik pisang mendapat untung Rp. 2,09 yang berarti bisnis keripik pisang patut dicoba. Strategi pengembangan yang dapat dilakukan oleh pengusaha keripik pisang adalah strategi agresif dengan lebih fokus pada strategi SO (Strength-Opportunities), yaitu dengan menggunakan kekuatan untuk memanfaatkan peluang yang ada. Strategi SO (Kekuatan-Peluang) meliputi: (a) Meningkatkan kapasitas produksi ekonomi untuk memenuhi permintaan, (b) Penggunaan Teknologi, (c) Memperbesar pangsa pasar, (d) Mempertahankan kualitas produk keripik pisang, dan (e) Membuat inovasi produk.

Kata kunci: biaya, pendapatan, rasio $\mathrm{R} / \mathrm{C}$, nilai tambah, strategi devoloping bisnis dan keripik pisang.

Sitasi: Naton S, D. Radiansah, H. Juniansyah, 2020. Analisis Nilai Tambah Dan Strategi Pengembangan Usaha Pengolahan Pisang Pada UMKM Keripik 3 Bujang Di Kota Pontianak , JSEP 16(2): 135 - 150.

\section{Pendahuluan}

Indonesia merupakan salah satu sentra produksi pisang dunia, yang memiliki 200 jenis pisang. Komoditi yang mudah rusak, memiliki kontribusi besar terhadap produksi buah-buahan nasional, memiliki potensi untuk ekspor.

Volume eskpor pisang Indonesia tertinggi dicapai pada tahun 2014 yaitu sebesar 26.694 ton dan volume terendah pada tahun 2010 yang hanya mencapai 14 ton atau turun $98 \%$ dari tahun sebelumnya 701 ton. Apabila dilihat dari pertumbuhannya, tahun 2011 merupakan pertumbuhan ekspor pisang yang paling tinggi hingga menembus $12.292,86 \%$, suatu pencapaian yang belum pernah tercatat kembali hingga saat ini.

Volume impor pisang Indonesia secara absolut lebih rendah dari volume ekspornya, hanya tiga kali tercatat volume impor lebih besar dibanding volume ekspor yakni tahun 2003, 2010 dan 2012. Tahun 2015 merupakan tahun yang paling menggembirakan karena tidak tercatat adanya kegiatan impor pisang ke Indonesia. Ketidakpastian kondisi pasar baik di domestik maupun dunia dengan sendirinya akan mempengaruhi pendapatan dan kesejahteraan petani pisang. Selain itu akan berpengaruh langsung juga terhadap devisa yang diterima. Berada pada posisi daya saing yang lemah, Indonesia diharapkan mampu meningkatkan nilai tambah produk pisang dan menyusun strategi pengembangan agar dapat bertahan dan bersaing dengan negara lainnya.

Kondisi agroindustri belum mampu menghasilkan produk yang berdaya saing tinggi. Agroindustri merupakan suatu subsistem pengolahan secara terpadu antara sektor pertanian dengan sektor industri sehingga akan diperoleh nilai tambah dari hasil pertanian. Industri pengolahan pangan adalah instrumen pemberi nilai tambah bagi komoditi pertanian. Oleh sebab itu, peran perusahan perusahan pengelohan pangan sangat penting bagi peningkatan nilai komoditi pertanian. 
Industri pengolahan tersebut berupa industri besar dan industri kecil maupun industri skala rumah tangga (Darmawan dkk,2004).

Salah satu industri tersebut adalah agroindustri keripik pisang. Pengolahan pisang menjadi keripik pisang, dilakukan oleh UMKM Keripik 3 Bujang. Memproduksi 4 varian rasa yaitu rasa cokelat, susu, balado, orginal dengan bahan baku pisang nipah. Penjualan produk tersebut juga tidak hanya dipasar disekitar lokasi produksi tapi juga sudah merambah di beberapa outlet bandara supadio pontianak dan juga pusat penjualan oleh-oleh di jalan patimura. Selain itu produk ini juga bisa dibeli secara online di bukalapak.

Pengembangan agroindustri banyak menghadapi kendala yang harus disikapi untuk tumbuh dan berkembang karena adanya faktor- faktor yang menghambat usaha kecil. Oleh karena itu, strategi pengembangan agroindustri untuk mengetahui faktor- faktor internal (kekuatan dan kelemahan) dan eksternal (peluang dan ancaman) yang dimiliki oleh industri pengolahan keripik pisang yang ditempuh harus disesuaikan dengan karakteristik dan permasalahan agroindustri yang bersangkutan.

Strategi pengembangan akan berpengaruh dalam menjaga daya saing atau eksistensi usaha dan mengatasi masalah masalah yang ada pada usaha agroindustri keripik pisang. Objek penelitian yang akan diamati selama penelitian yaitu UMKM Keripik Pisang 3 Bujang, yang berada di Jalan Serda Usman, Gang Keladan 3 No. 42 Perum 3, Tanjung Hulu, Pontianak Timur, Pontianak. Tujuan dari penelitian ini adalah mengetahui besar pendapatan dan keuntungan usaha keripik pisang dalam sebulan pada UMKM Keripik Pisang 3 Bujang dan mengetahui besar nilai tambah yang dihasilkan dalam sebulan proses pengolahan pisang menjadi keripik pisang pada UMKM Keripik Pisang 3 Bujang serta Strategi yang harus dilakukan dalam pengembangan usaha keripik pisang pada UMKM Keripik Pisang 3 bujang

\section{Metoda Penelitian}

\section{Lokasi dan Waktu Penelitian}

Penentuan daerah penelitian dilakukan secara sengaja (Purposive) yaitu pada usaha Agroindustri keripik pisang 3 bujang yang berlokasi di Jalan Serda Usman, Gang Keladan 3 No. 42 Perum 3,Tanjung Hulu, Pontianak Timur, kota Pontianak. Metode yang digunakan dalam pemelitian ini yaitu metode dekriptif dan analisis kuantitatif. Metode pengambilan sampel yang dilakukan pada penelitian ini adalah purposive sampling atau pengambilan sampel secara sengaja. Sampel yang dipilih melalui penetapan kriteria tertentu yang ditetapkan berdasarkan tujuan peneliti. Usaha pengolahan pisang yang digunakan sebagai lokasi penelitian sebanyak 1 unit usaha pengolahan pisang. 


\section{Pengumpulan Data}

Metode pengumpulan data yang digunakan yaitu data primer dan data sekunder. Metode yang digunakan untuk melengkapi data primer yaitu melalui observasi, wawancara, dan kuesioner. Teknik Observasi tentang proses produksi keseluruhan produk dan keadaan di usaha pengolahan untuk menganalisis pendapatan, keuntungan dan nilai tambah pada UMKM Keripik 3 Bujang dan wawancara untuk menganalisis strategi pengembangan baik dengan menggunakan kuesioner (daftar pertanyaan) yang telah dipersiapkan sebelumnya kemudian diberikan kepada 3 orang ahli untuk penentuan bobot dan 1 pemilik sebagai pemberi rating. Data primer berupa proses pengolahan, data penjualan olahan Keripik pisang serta faktor-faktor internal (kekuatan dan kelemahan) dan faktor-faktor eksternal (peluang dan ancaman) yang ada pada usaha keripik pisang dan berdampak pada usaha tersebut. Sedangkan data sekunder yang digunakan pada penelitian ini diperoleh dari penelitian terdahulu, jurnal, artikel, penelusuran pustaka.

\section{Analisis Data}

Analisis data yang digunakan pada penelitian ini yaitu analisis usaha yang meliputi analisis biaya, penerimaan, keuntungan dan R/C Ratio (bagian kedua adalah analisis nilai tambah (Added Value) (Hayami.,1987). Sedangkan bagian ketiga mengenai strategi pengembangan usaha pengolahan pisang pada UMKM keripik pisang 3 bujang menggunakan analisis SWOT. Adapun rincian variabel analisis sebagai berikut:

1. Analisis Biaya atau Total Cost (TC) merupakan keseluruhan biaya yang terdiri dari total biaya variabel atau Total Variabel Cost (TVC) dan total biaya tetap atau Total Fix Cost (TFC). Biaya yang digunakan dalam penelitian ini meliputi keseluruhan nilai dari masukan finansial yang secara riil dikeluarkan untuk membiayai proses produksi produk olahan pisang

$$
\mathrm{TC}=\mathrm{TVC}+\mathrm{TFC}
$$

2. Analisis Penerimaan atau Total Revenue (TR) merupakan keseluruhan uang yang diterima dari hasil sejumlah produk yang berhasil dijual atau perkalian dari jumlah produk yang dihasilkan $(\mathrm{Q})$ dengan harga jual produk $(\mathrm{P})$.

$$
\mathrm{TR}=\mathrm{P} \times \mathrm{Q}
$$

3. Analisis Keuntungan atau profit (П) merupakan selisih dari total penerimaan dengan total biaya yang dikeluarkan.

$$
\Pi=\mathrm{TR}-\mathrm{TC}
$$

4. R/C Ratio merupakan perbandingan antara penerimaan dengan biaya total.

$$
\mathrm{R} / \mathrm{C}=\frac{T R}{T C}
$$

Kriteria yang digunakan untuk menilai R/C Ratio adalah sebagai berikut:

$\mathrm{R} / \mathrm{C}$ Ratio $>1$ berarti usaha pengolahan produk pisang menguntungkan.

$\mathrm{R} / \mathrm{C}$ Ratio $<1$, maka usaha tersebut mengalami kerugian atau tidak layak untuk dikembangkan. 
$\mathrm{R} / \mathrm{C}$ Ratio $=1$, maka usaha berada pada titik impas (Break Event Point).

Perhitungan analisis nilai tambah dengan menggunakan Tabel Hayami memperhitungkan tiga variabel yang meliputi; output, input dan harga, Penerimaan dan keuntungan, serta balas jasa pemilik perusahaan. Tabel mengenai analisis nilai tambah menggunakan metode Hayami dkk.(1987) ditunjukkan oleh tabel berikut:

Tabel 1.Prosedur Perhitungan Nilai Tambah Hayami

\begin{tabular}{lc}
\hline \multicolumn{2}{c}{ Keluaran(Output), Masukan(Input) Dan Harga } \\
\hline Output/ produk total & $\mathrm{A}$ \\
Input Bahan Baku & $\mathrm{B}$ \\
Input Tenaga Kerja & $\mathrm{C}$ \\
Faktor Konversi & $\mathrm{D}=\mathrm{A} / \mathrm{B}$ \\
Koefisien Tenaga Kerja & $\mathrm{E}=\mathrm{C} / \mathrm{B}$ \\
Harga output & $\mathrm{F}$ \\
Upah Rata-rata Tenaga Kerja & $\mathrm{G}$ \\
\hline
\end{tabular}

Pendapatan dan Keuntungan

\begin{tabular}{lc}
\hline Harga Input bahan baku & $\mathrm{H}$ \\
Sumbangan input lain & $\mathrm{I}$ \\
Nilai Output & $\mathrm{J}=\mathrm{D} \times \mathrm{F}$ \\
Nilai Tambah & $\mathrm{K}=\mathrm{J}-\mathrm{I}-\mathrm{H}$ \\
Rasio Nilai Tambah & $\mathrm{L} \%)=(\mathrm{K} / \mathrm{J}) \times 100$ \\
Imbalan tenaga kerja & $\mathrm{M}=\mathrm{E}$ Xg \\
Bagian Tenaga Kerja & $\mathrm{N}(\%)=\mathrm{M} / \mathrm{K} \times 100$ \\
Keuntungan & $\mathrm{O}=\mathrm{K}-\mathrm{M}$ \\
Tingkat Keuntungan & $\mathrm{P}(\%)=(\mathrm{O} / \mathrm{J}) \times 100$ \\
\hline \multicolumn{1}{c}{ Balasan jasa untuk pemilik faktor-faktor produksi } \\
\hline Marjin & $\mathrm{Q}=\mathrm{J}-\mathrm{H}$ \\
Pendapatan tenaga kerja & $\mathrm{R}(\%)=\mathrm{M} / \mathrm{Q} \times 100$ \\
Sumbangan input lain & $\mathrm{S}(\%)=\mathrm{I} / \mathrm{Q} \times 100$ \\
\hline Keuntungan & $\mathrm{T}(\%)=\mathrm{O} / \mathrm{Q} \times 100$ \\
\hline
\end{tabular}

Metode yang digunakan untuk menganalisa permasalahan ketiga mengenai strategi pengembangan pada usaha pengolahan pisang pada UMKM Keripik Pisang 3 Bujang yaitu menggunakan analisis SWOT.

Menurut Rangkuti (2003) Analisis SWOT adalah identifikasi berbagai faktor secara sistematis untuk merumuskan strategi perusahaan. Analisis ini didasarkan pada logika yang dapat memaksimalkan kekuatan (Strenghts) dan peluang (Opportunities), namun secara bersamaan dapat meminimalkan kelemahan (Weaknesses) dan ancaman (Threats). Berdasarkan faktor internal dan eksternal yang telah ditentukan berdasarkan observasi, wawancara dan kuesioner dilapang maka langkah selanjutnya pemberian bobot pada masing-masing faktor. Kemudian dilakukan penentuan rating dan pemberian penjumlahan nilai pada masing-masing faktor internal dan eksternal. 


\section{Hasil Dan Pembahasan}

a. Analisis total biaya (total cost) produksi

Total biaya tetap yang harus dikeluarkan selama satu bulan (mei 2019) untuk kebutuhan pengolahan keripik pisang adalah senilai Rp 7.130.029. Adapun untuk kebutuhan biaya tidak tetap adalah Rp 14.900.000. Dengan demikian, secara keseluruhan total biaya yang harus dikeluarkan setiap bulan untuk produksi keripik pisang pada umkm keripik pisang 3 bujang.

$\mathrm{TFC}=\operatorname{Rp} 7.130 .029$

TVC $=\underline{\operatorname{Rp} 14.900 .000+}$

$\mathrm{TC}=\operatorname{Rp} 22.030 .029$

b. Analisis Total Pendapatan (Total Revenue)

Produksi dilakukan 4 (empat) kali dalam seminggu, dengan output produksi rata -rata sebanyak $24 \mathrm{~kg}$ keripik pisang dengan harga jual untuk ukuran 500 gram dan 150 gram seharga Rp 55.000 dan Rp 20.000 yang siap dipasarkan. Dengan demikian, jumlah pendapatan yang diterima UMKM Keripik Pisang 3 Bujang selama bulan Mei 2019, denga jumlah produksi sebanyak $16 \mathrm{kali}$ adalah $384 \mathrm{~kg}$ atau senilai Rp 46.090.00 perbulan.

Tabel 2. Pendapatan/ peneriman

\begin{tabular}{ccccc}
\hline \multirow{2}{*}{ No } & Ukuran & Jumlah Pack & Harga & Pendapatan \\
\hline 1 & 150 gram & 1.100 & 20.000 & 22.000 .000 \\
2 & 500 gram & 438 & 55.000 & 24.090 .000 \\
\hline & Total & 1.538 & & 46.90 .0 \\
\hline
\end{tabular}

c. Analisis Keuntungan

hasil keuntungan usaha produksi pengolahan keripik pisang pada UMKM Keripik Pisang 3 Bujang pada bulan Mei 2019 adalah sebesar Rp 46.090 .000 - Rp 22.030.029 = Rp 24.059.971. Hasil keuntungan sebesar Rp 24.059.971 merupakan keuntungan bersih yang diperoleh UMKM Keripik Pisang 3 Bujang.

d. Analisis R/C Ratio

Ratio $\mathrm{R} / \mathrm{C}=\frac{46.090 .000}{22.030 .029}=2,09$

$\mathrm{R} / \mathrm{C}$ rasio pada usaha mikro keripik pisang sebesar 2,09 atau 2 yang artinya $\mathrm{R} / \mathrm{C}$ rasio $>1$ maka usaha tersebut efisien dan usaha ini menguntungkan. Nilai $\mathrm{R} / \mathrm{C}$ rasio 2,09 atau 2 berarti dengan mengeluarkan biaya sebesar 1 satuan maka akan menghasilkan penerimaan sebesar 2,09 atau 2 satuan, maka usaha pengolahn keripik pisang layak diusahakan. 
e. Analisis Nilai Tambah

Tabel 3 Analisis Nilai Tambah

\begin{tabular}{|c|c|c|c|}
\hline No & Variabel & Satuan & Nilai \\
\hline \multicolumn{4}{|c|}{ output, Input, dan harga } \\
\hline 1 & output yang dihasilkan & $\mathrm{Kg} /$ proses produksi & 24 \\
\hline 2 & bahan baku yang digunakan & $\mathrm{Kg} /$ proses produksi & 100 \\
\hline 3 & input tenaga kerja & Hok/kg bahan baku & 1 \\
\hline 4 & faktor konversi & $\mathrm{kg}$ output/kg bahan baku & 0,24 \\
\hline 5 & koefisien Tenaga kerja & Hok/kg bahan baku & 0,01 \\
\hline 6 & Harga output & $\mathrm{Rp} / \mathrm{kg}$ & 110.000 \\
\hline 7 & upah rata-rata & $\mathrm{Rp} /$ proses produksi & 46.154 \\
\hline \multicolumn{4}{|c|}{ Nilai Tambah dan Keuntungan } \\
\hline 8 & harga input & $\mathrm{Rp} / \mathrm{kg}$ & 4.000 \\
\hline 9 & sumbangan input lain & $\mathrm{Rp} / \mathrm{kg}$ input & 7.286 \\
\hline 10 & nilai output & $\mathrm{Rp} / \mathrm{kg}$ & 26.400 \\
\hline \multirow[t]{2}{*}{11} & a. Nilai Tambah & $\mathrm{Rp} / \mathrm{kg}$ & 15.114 \\
\hline & b. Rasio Nilai Tambah & $\%$ & 57,25 \\
\hline \multirow[t]{2}{*}{12} & a. pendapatan Tenaga Kerja & $\mathrm{Rp} / \mathrm{Kg}$ & 461,54 \\
\hline & b.bagian tenaga kerja & $\%$ & 3 \\
\hline \multirow[t]{2}{*}{13} & a.keuntungan & $\mathrm{Rp} / \mathrm{kg}$ & 14.652 \\
\hline & b. Tingkat keuntungan & $\%$ & 96,94627 \\
\hline \multicolumn{4}{|c|}{ Balas Jasa Faktor Produksi } \\
\hline 14 & Marjin & & 22.400 \\
\hline & a. pendapatan Tenaga Kerja & $\%$ & 2 \\
\hline & b. Sumbangan input lain & $\%$ & 32,52679 \\
\hline & c. Keuntungan pengolahan & $\%$ & 65,41277 \\
\hline
\end{tabular}

Pada usaha pengolahan keripik pisang terlihat bahwa dengan menggunakan bahan baku pisang sebanyak $100 \mathrm{~kg} /$ sekali produksi dapat menghasilkan $24 \mathrm{~kg}$ keripik pisang. Usaha pengolahan keripik pisang menggunakan tenaga kerja $1 \mathrm{hk} /$ hari. Dengan demikian, koefisien tenaga kerja yangdibutuhkan untuk mengolah 100 $\mathrm{kg}$ pisang sebanyak 0,01. Harga produk rata-rata Rp 110.000,-/kg dengan faktor konversi sebesar 0,24. Hal ini dapat diartikan bahwa $1 \mathrm{~kg}$ pisang dapat menghasilkan keripik pisang sebesar 0,24 $\mathrm{kg}$. Dengan demikian, nilai produksi pada usaha pengolahan keripik pisang ini sebear Rp 26.400. nilai produksi ini dapat dialokasikan untuk bahan baku pisang sebesar Rp 4.000,- dan sumbangan input lain sebesar Rp 7.286 .

Besarnya nilai tambah dari produksi keripik pisang adalah Rp 15.114/kg. Nilai ini diperoleh dari nilai produk pengurangan harga bahan baku dan sumbangan input lain. Jadi apabila membuat keripik pisang $100 \mathrm{~kg}$ bahan baku pisang maka akan memproleh nilai tambaha sebesar Rp 15.114,- dengan rasio nilai tambah 57,25\% dari nilai produksi 
Dari hasil pengolahan data penelitian ini diperoleh bahwa pendapatan tenaga kerja $\mathrm{Rp} 461,5 / \mathrm{kg}$. Jadi artinya setiap penggunaan bahan baku pisang $1 \mathrm{~kg}$ maka tenagan kerja memdapatkan pendapatan sebesar $\operatorname{Rp} 461,54$ atau 3\% dari nilai tambah. Sedangkan keuntungan yang diperoleh dari usaha keripik pisang adalah Rp 14.652/ kg bahan baku dengan tingkat keuntungannya sebesar 96,95\% dari nilai tambah pada usaha keripik pisang.

f.Analisis Matrik IFAS Dan EFAS

1. Matriks IFAS

Tabel 4 Matriks IFAS Usaha Mikro Keripik Pisang "Keripik Pisang 3 Bujang”

\begin{tabular}{|c|c|c|c|c|}
\hline No & Pertanyaan & Bobot & Rating & Bobot $x$ rating \\
\hline \multicolumn{5}{|c|}{ Kekuatan } \\
\hline 1 & $\begin{array}{l}\text { Memiliki tenaga kerja keterampilan dan } \\
\text { pengalaman }\end{array}$ & 0,111 & 3 & 0,333 \\
\hline 2 & Sering melakukan promosi (pameran) & 0,122 & 3 & 0,367 \\
\hline 3 & Memiliki jaringan distribusi cukup baik & 0,122 & 3 & 0,367 \\
\hline 4 & Kualitas produk yang baik & 0,111 & 3 & 0,333 \\
\hline 5 & Memiliki serifikasi halal & 0,100 & 3 & 0,300 \\
\hline \multicolumn{4}{|c|}{ Total kekuatan } & 1,700 \\
\hline \multicolumn{5}{|c|}{ Kelemahan } \\
\hline 1 & Harga produk yang kurang ekonomis & 0,067 & 2 & 0,133 \\
\hline 2 & Teknologi lama & 0,089 & 3 & 0,267 \\
\hline 3 & Biaya produksi cukup tinggi & 0,089 & 3 & 0,267 \\
\hline 4 & Keterbatasan modal & 0,122 & 3 & 0,367 \\
\hline \multirow[t]{2}{*}{5} & Tempat produksi yang tidak memadai & 0,067 & 3 & 0,200 \\
\hline & Total kelemahan & 1 & & 1,233 \\
\hline \multicolumn{2}{|c|}{ Total keseluruhan } & & & 2,933 \\
\hline
\end{tabular}

Pada Tabel 4 dapat dilihat bahwa faktor kunci internal yang mempunyai skor kekuatan tertinggi adalah kualitas produk keripik pisang. Hal ini ditunjukkan oleh nilai bobot sebesar 0,122 dengan rating 3 dengan score 0,367. Faktor kunci ini merupakan peluang utama bagi usaha kecil keripik pisang ini karena sering melakukan promosi dan memiliki jaringan distribusi cukup baik memiliki tingkat kepentingan terbesar bagi pengembangan usahanya kedepan. Selain identifikasi terhadap kekuatan internal usaha mikro keripik pisang "Keripik Pisang 3 Bujang”, matriks IFAS juga menunjukkan berbagai kelemahan yang selama ini dimiliki usaha kecil keripik pisang ini. Faktor kunci internal yang menjadi kelemahan terbesar usaha ini adalah keterbatasan modal, yang memiliki bobot 0,122 dengan rating 3 sehingga skornya adalah 0,367.

Hasil analisis matriks IFAS pada usaha kecil keripik pisang ini yang meliputi seluruh faktor kunci internal (kekuatan dan kelemahan) adalah nilai skor sebesar 2,933. Total nilai tersebut menunjukkan bahwa usaha kecil keripik pisang ini berada pada level rata-rata di dalam kekuatan internal seluruhnya, sehingga usaha ini 
dituntut lebih optimal dalam memanfaatkan kekuatan yang dimiliki serta mereduksi kelemahan yang ada dalam mencapai keberhasilan usahanya.

\section{Matrik EFAS}

Tabel 5 Matriks EFAS Usaha Kecil Keripik Psang “Keripik Pisang 3 Bujang "

\begin{tabular}{|c|c|c|c|c|}
\hline No & Pernyataan & Bobot & Rating & Bobot $x$ rating \\
\hline \multicolumn{5}{|c|}{ Peluang } \\
\hline 1 & Permintaan relatif tinggi & 0,097 & 3 & 0,290 \\
\hline 2 & $\begin{array}{l}\text { Ketersediaan bahan baku yang } \\
\text { mudah }\end{array}$ & 0,118 & 3 & 0,355 \\
\hline 3 & $\begin{array}{l}\text { Adanya pembinaan baik dari } \\
\text { pemerintah dan lembaga terkait }\end{array}$ & 0,108 & 3 & 0,323 \\
\hline 4 & $\begin{array}{l}\text { Lokasi usaha yang terjamin dan } \\
\text { penyedian informasi }\end{array}$ & 0,097 & 3 & 0,290 \\
\hline 5 & Tidak dipengaruhi cuaca dan iklim & 0,086 & 1 & 0,086 \\
\hline & Total peluang & & & 1,344 \\
\hline \multicolumn{5}{|c|}{ Ancaman } \\
\hline 1 & Tingginya kompetisi usaha keripik & 0,097 & 4 & 0,387 \\
\hline 2 & $\begin{array}{l}\text { Muncul produk baru dengan kualitas } \\
\text { yang lebih unggul }\end{array}$ & 0,108 & 3 & 0,323 \\
\hline 3 & Teknologi baru & 0,097 & 1 & 0,097 \\
\hline 4 & Meningkatnya harga bahan baku & 0,086 & 3 & 0,258 \\
\hline 5 & Adanya peraturan bagasi berbayar & 0,108 & 2 & 0,215 \\
\hline & Total ancaman & & & 1,280 \\
\hline & total keseluruhan & 1,000 & & 2,624 \\
\hline
\end{tabular}

Sumber : hasil analisis (diolah)

Berdasarkan Tabel 5 menunjukkan bahwa faktor kunci eksternal yang memberikan peluang terbesar bagi usaha kecil keripik pisang "Keripik Pisang 3 Bujang", adalah Ketersediaan bahan baku yang mudah. Hal ini ditunjukkan oleh bobot terbesar yang dimiliki faktor kunci eksternal ini, yaitu sebesar 0,118 dengan rating sebesar 3 dan total skor 0,355. Bahan baku pisang termasuk komoditi yang tidak mengenal musim selain itu pula di kota pontianak termasuk yang berbatasan langsung dengan kabupaten yang memiliki komoditi pisang yang melimpah.

Faktor kunci eksternal yang memberikan ancaman terbesar bagi usaha kecil keripik pisang adalah Tingginya kompetisi usaha keripik. Hal ini ditunjukkan dengan nilai bobot sebesar 0,097 dengan rating 4 dan skor sebesar 0,387. Hal ini menunjukan tingginya kompetisi usaha keripik memiliki pengaruh yang signifikan dalam penjualan keripik pisang. Penjualan keripik pisang yang menurun, menyebabkan penurunan kapasitas produksi. Perubahan tersebut harus ditanggapi dengan bijak oleh pemilik usaha mikro keripik pisang ini, sehingga kelangsungan hidup usaha terjamin. Sejauh ini respon usaha mikro keripik pisang terhadap 
ancaman ini berada pada tingkatan yang kuat , hal ini terlihat dari besarnya rating yang diberikan.

Hasil analisis matriks EFAS pada usaha kecil keripik pisang "Keripik Pisang 3 Bujang" yang meliputi seluruh faktor kunci eksternal (peluang dan ancaman) adalah nilai skor sebesar 2,624. Total nilai tersebut menunjukkan bahwa usaha mikro berada pada level menengah dalam usahanya untuk menjalankan strategi yang memanfaatkan peluang eksternal atau menghindari ancaman yang ada dalam mencapai keberhasilan usahanya.

3. Analisis Matriks IE

Usaha mikro keripik pisang 3 Bujang berada pada nomor V yaitu pertahankan dan peliharan (hold andmaintain) berupa strategi penetrasi pasar (market penetrasion) dan pengembangan produk (product development). Kategori strategi pertahankan dan peliharaan meliputi strategi penetrasi pasar atau strategi pengembangan produk. Penetrasi pasar adalah upaya mencari pangsa pasar yang lebih besar, mencari targettarget pembeli baru, atau peningkatan pangsa pasar produk yang sudah ada melalui peningkatan usaha pemasaran. Apabila strategi tersebut dipilih, usaha mikro keripik pisang pada Keripik Pisang 3 Bujang harus memperluas cakupan area pemasaran yang telah ada sebelumnya. Perluasan ini diusahakan dapat mencakup daerahdaerah potensial yang belum dimasuki usaha lainnya. Perwujudannya dapat dilakukan melalui kegiatan-kegiatan promosi. Pengembangan produk dapat diupayakan melalui inovasi-inovasi pada produk yang dihasilkan. Di antara dari inovasi-inovasi tersebut adalah meningkatkan standar mutu hasil produk, meningkatkan teknologi untuk proses produksi, dan lain-lain. Contoh perwujudannya dapat dilakukan dengan memberi standar kualitas keripik pisang, mengadakan teknologi baru.

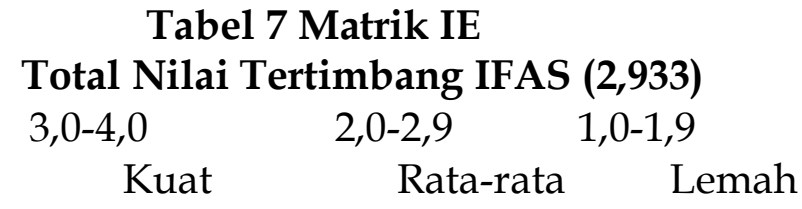

$\begin{array}{ll}\text { Total Nilai } & \text { Tinggi } 3,0-4,0 \\ & \text { Rata-rata } 2,0- \\ \text { Tertimbang } & 2,9 \\ & \text { Rendah } 1,0-1,9\end{array}$

\begin{tabular}{ccc} 
I & II & III \\
\hline IV & $\begin{array}{c}\text { V( usaha } \\
\text { pengolahan })\end{array}$ & VI \\
\hline VII & VIII & IV
\end{tabular}


4. Matriks SWOT

Tabel 8 Matrik SWOT

\begin{tabular}{|c|c|c|}
\hline $\begin{array}{ll}\text { EFAS } & \text { IFAS }\end{array}$ & (Strenght) Kekuatan & (Weaknesses) Kelemahan \\
\hline $\begin{array}{l}\text { (Opportunities) } \\
\text { Peluang }\end{array}$ & $\begin{array}{l}\text { Strategi SO } \\
\text { (Agresif) } \\
1,700+1,344=3.044\end{array}$ & $\begin{array}{l}\text { Strategi WO } \\
\text { (Turn-Around) } \\
1,233+1,344=2.577\end{array}$ \\
\hline $\begin{array}{l}\text { (Threats) } \\
\text { Ancaman }\end{array}$ & $\begin{array}{l}\text { Strategi ST } \\
\text { (Diversifikasi) } \\
1,700+1,280=2.980\end{array}$ & $\begin{array}{l}\text { Strategi WT } \\
\text { (Defensif) } \\
1,233+1,280=2.513\end{array}$ \\
\hline
\end{tabular}

Dari Tabel diatas bisa disimpulkan bahwa kekuatan + peluang $(\mathrm{SO})=3,044$, peluang + kelemahan $(\mathrm{WO})=2,577, \quad$ kekuatan $+\operatorname{ancaman}(\mathrm{ST})=2,980$, dan kelemahan tancaman $(\mathrm{WT})=2,513$. Sehingga dalam perencanaan strategi ini yang harus dilakukan keripik pisang 3 bujang adalah memanfaatkan strategi (SO) yang memiliki nilai 3,044, yang lebih tinggi dari nilai WO,ST dan WT.

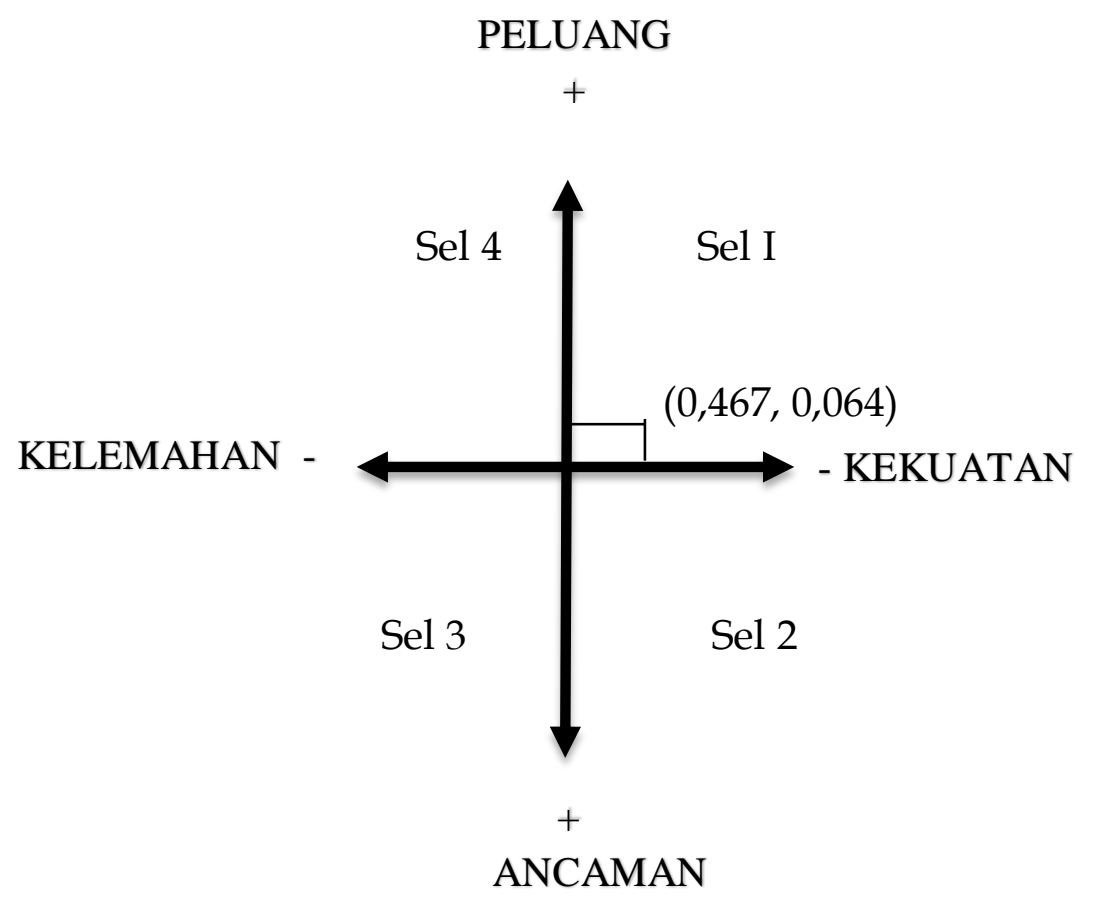

\section{Gambar 1 Diagram SWOT}

Selisih antara skor kekuatan dan kelemahan $(0,467)$ dimasukkan pada sumbu$x$, sedangkan selisih antara skor peluang dan ancaman $(0,064)$ dimasukkan pada sumbu-y. Dari keduanya ditarik garis lurus yang saling berpotongan pada Sel I. Nilai selisih kekuatan dengan kelemahan yang bernilai Kekuatan positif dan selisih peluang dengan ancaman yang bernilai positif menunjukkan bahwa usaha mikro Keripik Pisang 3 Bujang dalam kondisi kuat dan berpeluang, sehingga sangat 
memungkinkan untuk terus melakukan ekspansi, memperbesar, pertumbuhan dan meraih kemajuan secara maksimal.

5. Rumusan Strategi

Berdasarkan keempat kategori strategi yaitu SO (3.044),WO (2.577), ST (2,980), WT (2,513). Alternatif strategi yang dapat dilakukan untuk pengembangan usaha mikro keripik pisang 3 bujang adalah SO. Hal ini disebabkan karena nilai SO lebih tinggi dari pada nilai yang lainnya.

1. Strategi SO

- Meningkatkan kapasitas produksi secara ekonomis untuk memenuhi permintaan.

- Penggunaan teknologi

- Memperbesar market share

- Mempertahankan kualitas produk keripik pisang

- Melakukan inovasi produk

Strategi tersebut didapatkan dari pihak internal selaku pengusaha, didukung pendapat ahli dan penelitian terdahulu sebagai berikut:

Menurut pendapat Freddy Rangkuti (2005), Kapasitas adalah tingkat kemampuan berproduksi secara optimum dari sebuah fasilitas biasanya dinyatakan sebagai jumlah output pada satu perode waktu tertentu. Manajer Operasional memperhatikan kapasitas karena; pertama, mereka ingin aabmencukupi kapasitas untuk memenuhi permintaan konsumen. Kedua, kapasitas mempengaruhi efisiensi biaya operasi. Ketiga, kapasitas sangat bermanfaat mengetahui perencanan output, biaya pemiliharan kapasitas, dan sangat menentukan dalam analisis kebutuhan investasi. Menurut penelitian MA Prasnowo, dkk (2017), yang berjudul Strategi Pengembangan Sentra Industri Kecil Menengah Produksi Krupuk. Strategi meningkatkan kapasitas produksi ini agar bisa mencukupi kebutuhan pasar yang mengalami peningkatan, serta bisa menjaga persaingan yang semakin ketat.

Market share menurut (Assauri, 1980) adalah besarnya bagian atau luasnya total pasar yang dapat dikuasai oleh suatu perusahan yang biasanya dinyatakan dalam persentase. Untuk dapat bertahan pada pangsa pasar yang sama dibutuhkan strategi pemasaran yang efektif. Salah satunya strategi yang efektif adalah dengan keunggulan bersaing suatu perusahan. Menurut penelitian A. Bayu Purnomo (2012), yang berjudul "Strategi Pengembangan Agroindustri Keripik Pisang" dengan prioritas strategi pengembangan pasar.

Menurut Ukudi (2017), konsep kualitas produk telah menjadi faktor yang sangat dominan terhadap keberhasilan organisasi, baik organisasi profit maupun non profit, karena apabila konsumen merasa bahwa kualitas produk yang diterimanya baik atau sesuai harapan, maka akan merasa puas, percaya dan mempunyai komitmen menjadi konsumen yang royal. Menurut penelitian A. Pratiwi, dkk (2017), yang berjudul “Analisis Swot Pada Umkm Keripik Tempe Amel Malang Dalam Rangka Meningkatkan Daya Saing Perusahaan"meningkatkan 
kualitas produk Keripik Tempe“Amel”sehingga dapat bersaing dengan keripik tempe lain serta melakukan inovasi produk sehingga mempunyai keunggulan yang berbeda dari keripik tempe lain.

Menurut Hubeis (2012), inovasi produk merupakan pengetahuan produk baru, yang sering kali dikombinasikan dengan hal baru untuk membentuk metode produksi yang tidak diketahui. Menurut Penelitian H. Nadhia Hayyu (2017), yang berjudul "Strategi Pengembangan Industri Keripik Tempe" meningkatkan variasi produk dari segi rasa seperti pedas barbeque, rumput laut atau sesuai dengan permintaan konsumen.

\section{Kesimpulan}

Berdasarkan uraian hasil dan pembahasan, maka dapat disimpulkan dalam penelitian ini:

1. Total biaya yang dikeluarkan oleh UMKM Keripik Pisang 3 Bujang dari adanya proses produksi pisang menjadi keripik pisang pada bulan Mei 2019 adalah sebesar Rp 22.030.029 dan pendapatan/peneriman yang diperoleh adalah sebesar Rp 46.090.000, sehingga keuntungan yang dihasilkan adalah Rp 24.059.971.

2. R/C Rasio pada usaha mikro pengolahan keripik pisanag adalah sebesar 2,09. Setiap pengeluaran biaya sebesar Rp 1,00 maka UMKM Keripik Pisang 3 Bujang akan mendapatkan penerimaan sebesar Rp 2,09 sehingga usaha mikro memperoleh keuntungan sebesar Rp 1,09. Dengan demikian UMKM keripik Pisang 3 Bujang layak untuk diusahakan.

3. Pengolahan pisang menjadi keripik pisang pada UMKM keripik pisang 3 bujang di Kota Pontianak menghasilkan nilai tambah sebesar Rp15.114/ kg bahan baku.

4. Strategi pengembangan yang dapat dilakukan UMKM Keripik Pisang 3 Bujang sebagai alternatif strategi adalah Strategi agresif dengan lebih fokus kepada strategi SO (Strength- Opportunities), yaitu dengan menggunakan kekuatan untuk memanfaatkan peluang yang ada. Strategi SO (Strength-Opportunities) meliputi: (a) Meningkatkan kapasitas produksi secara ekonomis untuk memenuhi permintaan, (b) Pengunaan Teknologi, (c) Memperbesar market share, (d) Mempertahankan kualitas produk keripik pisang, dan (e) Melakukan inovasi produk.

\section{Daftar Pustaka}

Affandi, M. I., Kalsum, U., Agribisnis, J., Pertanian, F., Lampung, U., Prof, J., \& Brojonegoro, S. (2017). ( Financial and Added Value Analysis of Micro and Small Scale Banana Chip Agroindustries in Metro City ), 5(1), 48-56

C.Steffi S., Saragih., Salmiah.,Dan Diana Chalil. Analisis Nilai Tambah Dan Strategi Pengembangan Pengolahan Ubi Kayu Menjadi Tepung Mocaf (Modified Cassava Flour), Universitas Sumatera Utara. 
Diarsa, A.W.,Dkk,(2017). Analisis Nilai Tambah Dan Strategi Pengembangan Home Industry Kupang Kering Di Desa Balongdowo Kecamatan Candi Kabupaten Sidoarjo, Vol 10 No. 3, Universitas Jember.

Firdaus, M.(2017).Manajemen Agribisnis.Jakarta(ID): PT. Bumi Aksara.

Hasanah, Uswatun., Mayshuri.,Dan Djuwari.(2015). Analisis Nilai Tambah Agroindustri Sale Pisang di Kabupaten Kebumen,Vol. 18 No.3, pp. 141 -149, Universitas Gadjah Mada, Yogyakarta.

L,Aminah, Nur ,M.,(2013). Analisis Nilai Tambah Dalam Pengolahan Susu Kedelai Pada Skala Industri Rumah Tangga Di Kota Medan [Skripsi]. Medan (ID): Universitas Sumatera Utara Medan.

Lestari,Y.A.(2017).Analisis Pendapatan, Nilai Tambah Dan Strategi Pengembangan Usaha PengolahanIkan Bandeng Pada Usaha Dagang Sabily Kecamatan Labuhan MaringgaiKabupaten Lampung Timur[SKRIPSI].Lampung (ID): Universitas Lampung.

Mislana (2014). Analisis Keuntungan Berbagai Pola Tanam Usahatani Jahe Dan Sayur Di Desa Sungai Rasau Kecamatan Sungai Pinyuh Kabupaten Pontianak [Skripsi]. Pontianak(ID): Universitas Tanjungpura.

Mubarok, A. A., Arsyad, A., \& Miftah, D. H. (2015). ANALISIS NILAI TAMBAH DAN MARGIN PEMASARAN PISANG MENJADI OLAHAN PISANG ANALYSIS OF ADDED VALUE AND MARKETING MARGIN OF PROCESSED BANANA PRODUCTS. Jurnal Pertanian ISSN 2087 (Vol. 4936).

Peternakan, F., Dan, I., Karangmalang, J. F., Yogyakarta-, K. U. G. M., Organisasi, P., Bisnis, D., \& Ketiga, A. R. M. (n.d.). Buku 2 : BAHAN AJAR ( Rencana Kegiatan Pembelajaran Mingguan ) < Modul Pembelajaran Pertemuan ke 3 > MANAJEMEN AGROBISNIS Semester IV / 3 SKS / PTE 2102.

Pusat Data dan Sistem Informasi Sekretaris Jendral Kementrian Pertanian. (2016). Outlook Komoditas Pisang. Komoditas Pertanian Sub Sektor Hortikultura, 61.

Sari,A.S.,Lily, Z., dan Emalisa. Analisis Nilai Tambah Pengolahan Ubi Kayu Menjadi Tape Ubi Studi Kasus: Kelurahan Baru Ladang Bambu, Kecamatan Medan Tuntungan, Kota Medan Universitas Sumatera Utara.

Siregar,S. A.P., Salmiah.,Dan At Hutajulu. Analisis Nilai Tambah Dan Strategi Pengembangan Usaha Industri Pengolahan Rotan (Calamus, Sp) Menjadi Furnitur Di Kota Medan,Universitas Sumatera Utara.

Soehyono, F., Rochdiani, D., \& Yusuf, M. N. (2017). Analisis Usaha Dan Nilai Tambah Agroindustri Tempe. Jurnal Ilmiah Mahasiswa Agroinfo Galuh, 1(1), 43. https://doi.org/10.25157/jimag.v1i1.286

Soemarno, D., Mawardi, S., Maspur, M., \& Prayuginingsih, H. (2009). Kabupaten Bengkulu Tengah. Agr, 25(1), 35-85.

Sugiyono.(2018).Metode Penelitian Kuantitatif, Kualitatif, dan R\&D. Bandung(ID):Alfabeta CV. 